\title{
$\mathrm{V}-3 \cdot 1$ 二 相 流 動*
}

山崎彌三 郎**

蒸発装置内の流勘については化学工学便覧では項目が 設けられていないが，その型式が多種多様であるため流 動の閣題も各方面にわたる。たと点ば圧降下については 垂直管内，水平管内の蒸発を伴なら二相流動の問題があ り，また原子灿などの熱流索の大きい場合には表面沸騰 を伴なら流れの問題がある。さらに別項のェントレーメ ント在除いても気体容皘率, 二相流臨界速度, 自然循環. 流れの安定性の問題があり, 液体も水以外の高粘度淮・ 臨濁液に应がるが今回は水一藻父采を主とする。上記の よ5な問題はボイラ関係で研究されてきたが，最近の原 子力特に沸滕水型炉の開発に伴なって進步を示した。

\section{V-3·1-1 蒸発を伴なう二相流動（一成分系）}

二相流動のレビュー19)の不足な点を補足しながら記 す。種々の不備な点は指摘されているが，今までのとこ ろ，とくに常压以外の所の設計計算に使用されているの は，一貫して使いよくできている Martinelli \& Nelson の方法13)である。この方法は蒸発の起っている管の長さ 方向について圧降下老積分したもので，その際蒸発によ る流速増大のための加速度の項 $\left(\Delta P_{a}=r_{2} \frac{G^{2}}{g}\right)$ を補正 したものである。すなわち

$$
\begin{aligned}
\Delta P_{T P} & =\Delta P_{L O}\left(\frac{\Delta P_{T P F}}{\Delta P_{L O}}\right)+\Delta P_{a}=\frac{f_{f} G^{2}}{2 g_{c} \rho_{L} D} \int_{0}^{L_{B}} R d L \\
& =\bar{R} \frac{f_{f} G^{2} L_{B}}{2 g_{c} \rho_{L} D} \\
\text { ここで } &
\end{aligned}
$$

$$
R \equiv \frac{(d P / d L)_{T P F}}{(d P / d L)_{L O}}
$$

計算に必要な数值は線図などで与えられているので計算 すべき值は $\Delta P_{L O}{ }^{* * * *}$ のみである。この方法は気一液相共 に乱流であること，熱流束は管長方向に一定であること を仮定し，データは二成分系の女の在使用し，かつ死力 の影暗は臨界点附近の值から推算した点に注意を要す る。したがって乾き度 $(x)$ の分布が線型でない時には区 間にわけて計算する必要がある11。彼らはこの方法に上 る予测值の舁䮖值との比較は行なわなかった。Jakob，

* 昭和 36 年 1 月 26 日受理

*** 日本原子力研究所化学工学研究室

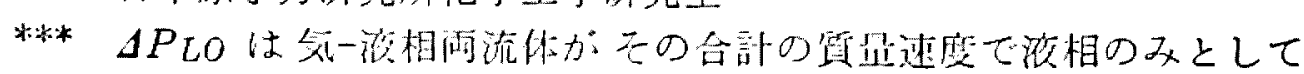
流九たとしたときの王降下で石油则原では $A P L^{*}$ とさくことが多い。前
Leppert ${ }^{9)}$ らは強倒対流均一加熱の水平蒸発管 $\left(3 / 8^{\prime \prime}\right)$ の実験で全王力損失 $\Delta P_{T P}$ についての実験式を提出し た。すなおち

$$
\frac{\Delta P_{T P}}{\Delta P_{L O}}-1=(1.41-520 \log P) x_{e}{ }^{1.17}
$$

ただし $P$ : psia， $x_{e}$ : 出口蒸気乾き度。彼らの実験範 用（出口压力 $30 \sim 300 \mathrm{psia}$, 流量 $110 \sim 360 \mathrm{lb}$, 熱流束 350,000 B.t.u. $/ \mathrm{hr} \cdot \mathrm{ft}^{2}$ 蒸発量最大 $44 \%$ まで)については かなり一致する。Dengler 2) の䒠験は生力 7.2〜29 psia， 熱流束 $0 \sim 200,000$ B.t. u. $/ \mathrm{hr}^{\circ} \mathrm{ft}^{2}, \quad x_{e}=0 \sim 100 \%$ ，流量 $240 \sim 5,500 \mathrm{lb} / \mathrm{hr}$ で垂直上易管（直径 $1^{\prime \prime}$, 屒さ $20 \mathrm{ft}$ ) について行なわ机た。 $R_{L}$ 在求妨て $\Phi_{L}$ を求めたところ Martinelli の值上り約 $20 \%$ 大きく，熟真荷が大きい特 は300\% 位になった。また正降下の大部分は上部の数 $\mathrm{ft}$ で起る。Westmoreland ${ }^{18)}$ は二相流のモデルとして壁面 に液相のある環状流を取り, 垂直管の $\Delta P_{T P F}$ を液一乱流, 気一層流として計算した結果, 気体容積掌*****がささ 時 (0.7 以下) はMartinelli-Nelsonの結果と常圧附近て やや過大になるほかよく一致した。また 500 psia では ぞの流れの組合わせで計算しても $R_{g}<0.7$ ではほぼ同 一の值を示した。また Lottes \& Flinn ${ }^{10)}$ は簡単な罡状 流モデルから $\bar{R}$ についての式を

$$
\bar{R}=\frac{1}{3}\left[1+\frac{1}{1-R_{g e}(1-\Psi)}+\left(\frac{1}{1-R_{g e}(1-\Psi)}\right)^{2}\right]
$$

$$
\text { ただし } \Psi \equiv \frac{u_{G}}{u_{L}} \cdot \frac{\rho_{G}}{\rho_{L}} \text { 断熱の時 } \bar{R}=R=\left(\frac{1-x}{1-R_{g}}\right)^{2}
$$

と与光，堅型の実験と比べたが圧力の影響が不十分でお， り，また $R_{g}$ の大きいところでは不適当である。また断 熱二成分系データと比べると $R_{g}<0.5$ 流量 $10^{6} \mathrm{Ib} / \mathrm{hr} \cdot \mathrm{ft}^{2}$ で一致する ${ }^{12)}$ 。Martinelli の方法では全流量 $(G)$ によ って $\Phi_{L}{ }^{2}$ または $\Phi_{G O}{ }^{2}$ は变化しない筈であるが Isbin ${ }^{72}$ らの水平断熱管 $\left(0.484^{\prime \prime} \cdot 1.062^{\prime \prime}\right)$ のデータでは比較的 低圧 (100 psig 以下) でも $\Phi_{L}$ は圧力のみならず流量に よって変化するし， $x>0.7$ では Martinelli のカーブと 平行でなくなる。 $\Phi_{G O}{ }^{2}$-x を取れば圧力の影暗は少なく

因のレビューではこの記法に統一したが今回は添字として $O$ を使う記法 に統一した。 $\Phi_{L O}, \Phi_{G O}$ なども同椂。

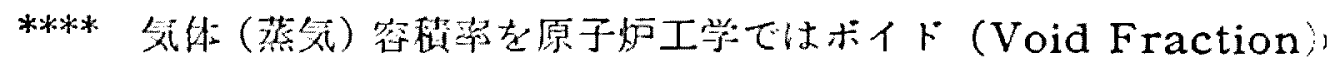
と言い、 $a$ または $R_{g}$ (二成分系と同じ記号)で椓加す。 


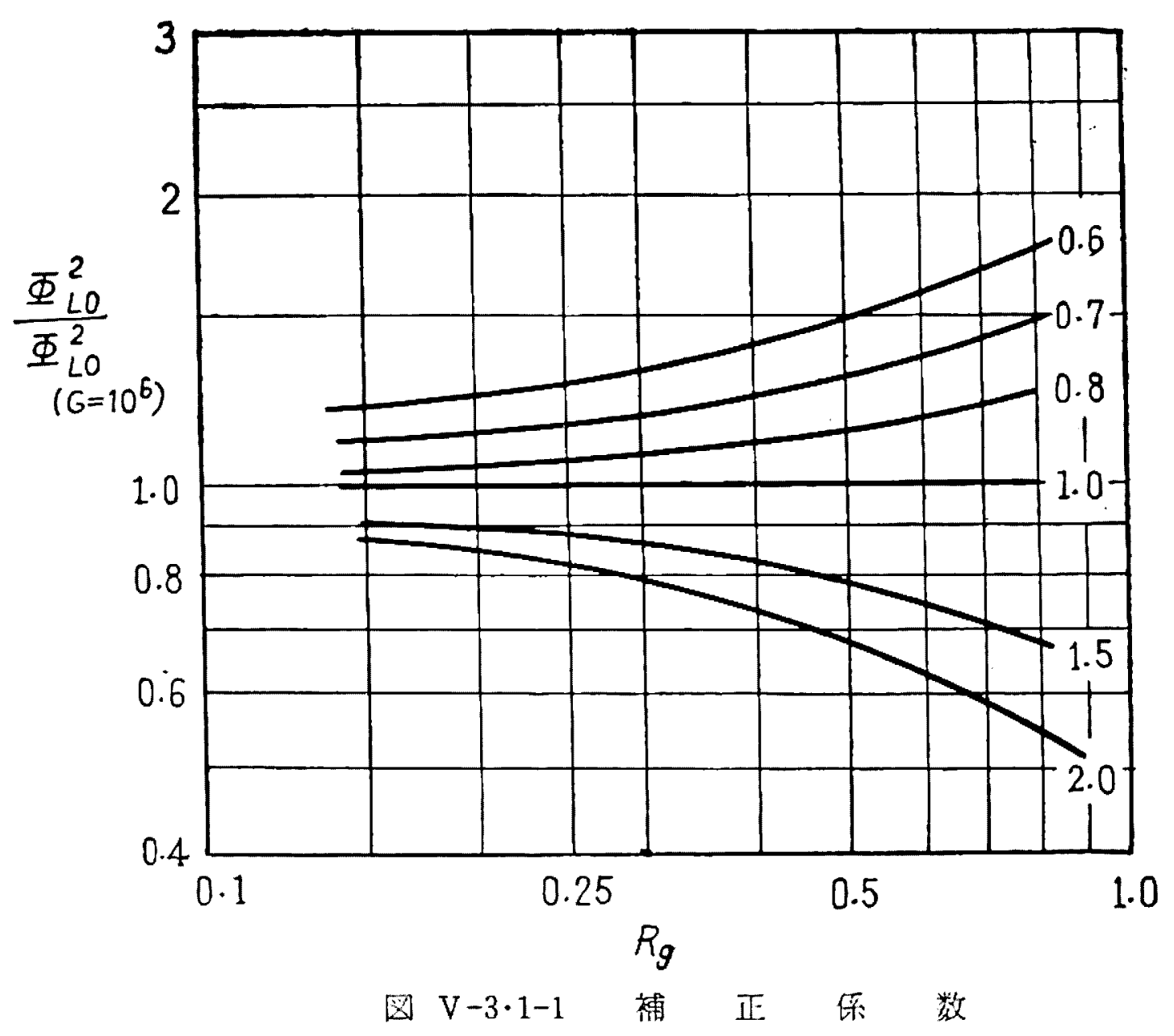

なるが流量および $x$ の影響は残る。さらに 400〜 1,415 psig でも $\Phi_{G O}{ }^{2}$ をとると圧力の影響は小さいが流量につ いて大中小のグループに分ける必要が生じた。な招 400 〜 1,415 psig では $G>10^{6}$ では摩擦係数をとる方法で 0.7 1.2 倍の範囲で尒测できる。Marchaterre ${ }^{11)}$ は上 記データのほか Petrick の垂直管の二成分系の, および Sher ${ }^{15)}$ の 2,000 psi での一成分系の圧降下データが $G<$ $10^{6} \mathrm{lb} / \mathrm{hr} \cdot \mathrm{ft}^{2}$ 以外では Martinelli の值から離れたこと に着目し，設計計算用としてSher が提案した方法で作っ た $G$ 拈よび $R_{g}$ についての補正倸数 $\left(\Phi_{L O}{ }^{2}\right.$ について）表 を使って計算する方法 (Modified Martinelli Method) [図 V-3・1-1] を提出した。これによると実験值と士20 \%くらいの誤差で計算できる。しかしこのまとめ方は あくまで設計のためのもので, 一成分采の王降下の值が 流量によって，また 值と合わないことの原因およびデータの合理的な相関法 については未解決である。な擐状路については Hoopes ${ }^{4)}$ おび Bonilla, Bendler ら ${ }^{16)}$ を参照。

\section{$\mathrm{V}-3 \cdot 1-2$ 表面沸騰のある時の王降下}

シェットェンジン・原子炉のように熱流束の大きい場 合には，主流流体が飽和温度以下でも伝熱面で沸騰が起 る。この場合蒸気泡のあるものは壁面を離れ液本体中で 潰れるので, 平均密度は下り王降下も增光単相の $2 \sim 3$ 倍になることもある。Buchberg ${ }^{1)}$ らは垂值管 $\left(0.226^{\prime \prime}\right.$ 長さ 24.6") について化力 $100 \sim 2,000$ psia, 流速 5 30 $\mathrm{ft} / \mathrm{sec}$, 熱流束 $2,000,000$ B.t.u $/ \mathrm{hr} \cdot \mathrm{ft}^{2}$ までについての 浔験で，压降下は一定流量，一定サブクーリングでは熱 流速が增与につれて大きくなるが，压力が低い汪ど增加 が速かである。この絬果をまとめた式をもあるが次の Reynolds $^{14)}$ の式がよい。長さ $L$ の全圧降下 $\Delta P_{L B}$ は
$\Delta P_{L B}=\left(\frac{d P}{d L}\right)_{L} \frac{G D c_{p}\left(\Delta T_{\mathrm{sub}}\right)_{O}}{4 a q^{\prime \prime}} \sinh \left(\frac{4 a q^{\prime \prime} L}{G D c_{p}\left(\Delta T_{\mathrm{sub}}\right)_{O}}\right)$

（水柱 in）

$$
a=4.6\left(\frac{q^{\prime \prime}}{10^{6}}\right)+1.2, \quad\left(\frac{d P}{d L}\right)_{L}: \text { in of } \mathrm{H}_{2} \mathrm{O} / \mathrm{ft}
$$

实験は水平管, 直径 3/8", 長さ $6 \mathrm{ft}$, 熱流束 $130,000 \sim$ 304,000 B.t. u. $/ \mathrm{hr} \cdot \mathrm{ft}^{2}$, 流量 $343 \sim 652 \mathrm{lb} / \mathrm{sec} \cdot \mathrm{ft}^{2}$, 圧力 45〜 100 psia. なお Sher 当式を出している15,8)。

\section{$\mathrm{V}-3 \cdot 1-3$ 臨界流速}

二相流も圧縮性流体の一種であるからパイプ中を流れ 得る最大速度が存在する。いま摩擦損失のない断熱膨張 (等エントロピー膨張)を考えると最大流星は $(\partial G / \partial P)_{S}$ $=0$ 加 $G_{\max }=\sqrt{g_{c}\left(-\frac{\partial P}{\partial v}\right)_{S}}, v ：$ 比体䅡，蒸発管 でも圧力が低く，熱流束が大きいと管出口で臨界流量に 達することがある。 $G_{\max }$ は二相の等速度と相間の平衡 状態を仮定寸れば蒸気表から計算できる济が, Stein ら は下降流および他のデータからその150\%くらいになる ことが珍らしくないことを示した。Isbin らは圧力 4〜 $43 \mathrm{psia}$, 乾き度 $1 \sim 100 \%$ について $1 / 4^{\prime \prime}, 1 / 2^{\prime \prime}, 3 / 4^{\prime \prime}$, l”管などについて测定しグラフで結果を与えた。

\section{$\mathrm{V}-3 \cdot 1-4$ 二相流の気体容積率}

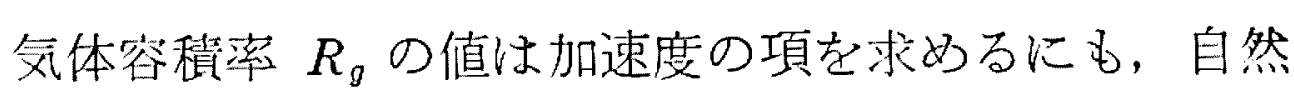
循環の平均密度の計算にも必要であるが，原子炉では炉 の反応度にも関倸があるので重要である。蒸発管内では 乾き度と $R_{g}$ との間には次の閔係が成り立つ。

$$
\frac{u_{G}}{u_{L}}=\left(\frac{x}{1-x}\right)\left(\frac{\rho_{L}}{\rho_{G}}\right)\left(\frac{1-R_{g}}{R_{g}}\right)
$$

これは滑り比と呼ばれ設計に便利な值で, 蒸発管の出口 の滑り比と圧力・入口流速などの関倸江 Lottes ${ }^{10,11)} ら$ により与党られている。しかし $R_{g}$ についての相觉が進 めば $R_{g}$ と $x$ との関係は $u_{G} / u_{L}$ を経ずに求められるべ きものである。

Martinelliの $R_{g}$ と $x$ との関倸(パラメーターは圧力) は任降下々同様実験で確かめられたものではない。Isbin らの测定結果によれば Martinelli の值より低い6)。

\section{$\mathrm{V}-3 \cdot 1-5$ 自然循環}

自然循環の計算山拦来先の必要性を認められていた が，相当面倒であることと啇用すべきデータの不足から 殆んど行なわれなかったが，これも原子炉に関連して計 算法が発展した。Harvey \& Foust ${ }^{5)}$ は一次元の二相流 の流動方程式などを導きこれを自然循環の計算に使用し た。この方法は相対速度が0の場合に限られるので，広 い籁囲に使らには㸡限があって不便である。他にも 1,2 
の相刘速度 0 のときの循環の解析があるが省略寸る。

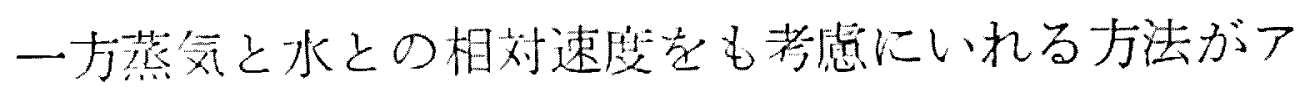
メリカの Argonne National Laboratory で発達した。 これは基本的には Lottes \& Flinn ${ }^{10)}$ の示した方法であ るが、これを補足し正降下の計算に前記の“修正マルテ ィネリ法”を使ってまとめたのが ANL-6063 の方法で ある11)。計算は一未の蒸発管 (図 V-3・1-2)について行 なったもので夷験とも比較した。定常状態では全システ ム中で

$$
\Sigma \Delta P=0
$$

この $A P$ はループを上部プレナムよりの収縮部，ダウン カマ一内，下部プレナムへの彭镸，下部プレナム内，下

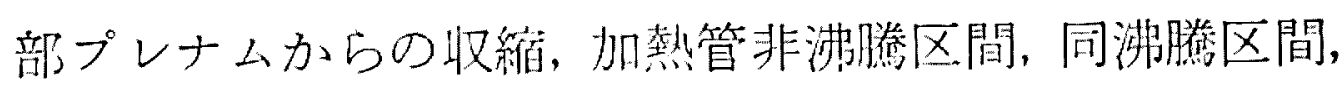
ライザーへの兴张と収維, 上部プレナムへの膨張とわけ， それぞれについて全王降下を求める式老作る。これを整 理すれば盾罡の推進力は $\left(\bar{\rho}_{D}-\bar{\rho}_{N B}\right) L_{N B}+\left(\bar{\rho}_{D}-\bar{\rho}_{B}\right) L_{B}+$ $\left(\bar{\rho}_{D}-\bar{\rho}_{R}\right) L_{R}$ で, 求めるものは循愣速度（飽和温度にお ける速度） $u_{0}$ である。

一方加熱管内では熱收支として

$$
Q_{T}=\rho_{L} A u_{0}\left[\left(h_{f}-h_{i n}\right)+x_{e} h_{f g}\right]
$$

物質収支として出口に扣いて

$$
\frac{W_{G}}{W_{L}}=\frac{x W_{T}}{(1-x) W_{T}}=\frac{\rho_{G} R_{g_{e}} A u_{G}}{\rho_{L}\left(1-R_{g_{e}}\right) A u_{L}}
$$

または

$$
x_{e}=\frac{1}{1+\left(\frac{u_{L}}{u_{G}}\right)\left(\frac{\rho_{L}}{\rho_{G}}\right)\left(\frac{1}{R g_{e}}-1\right)}
$$

が成立する。

計算はまず（1）出口の気体容程率 $R_{g_{e}}$ を仮定し，(2) 滑り比を 11），12）などで求めて（8）式より $x_{e}$ を求め る，(3） $L_{B}$ を $\frac{L_{B}}{L_{T}}=\frac{W_{T} x_{e} h_{f g}}{Q_{T}}$ 加計算し（6）式を解 いて $u_{0}$ を求め，(4) 滑り比党 $u_{0}$ から求めて必要が击れ ば反復計算する，（5） $x_{e}$ と $u_{0}$ から（7）に上り出力が 求められる。この計算悴数を多くとると于数がかかる が計算機を利用して解いた例が笔表されている3。。の

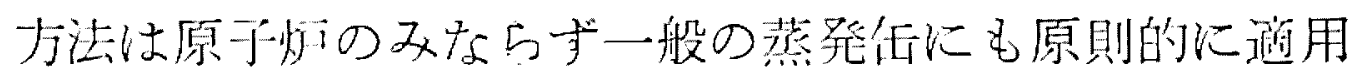
しうるものであるが，スチーム加熱では熱流束は一定で なく流速により なる。亦大强制循璪も同渌にして解くことができる。こ れらの計算には 1〜4の各項についての正しい值が必要 であるが，まだすべての籍围について淽足すべき数值が 得られていないので明究が進行中である。

\section{$\mathrm{V}-3 \cdot 1-6$ 流れの安定性}

白然偱環ルーブを定常状態で計算して結果を求めても

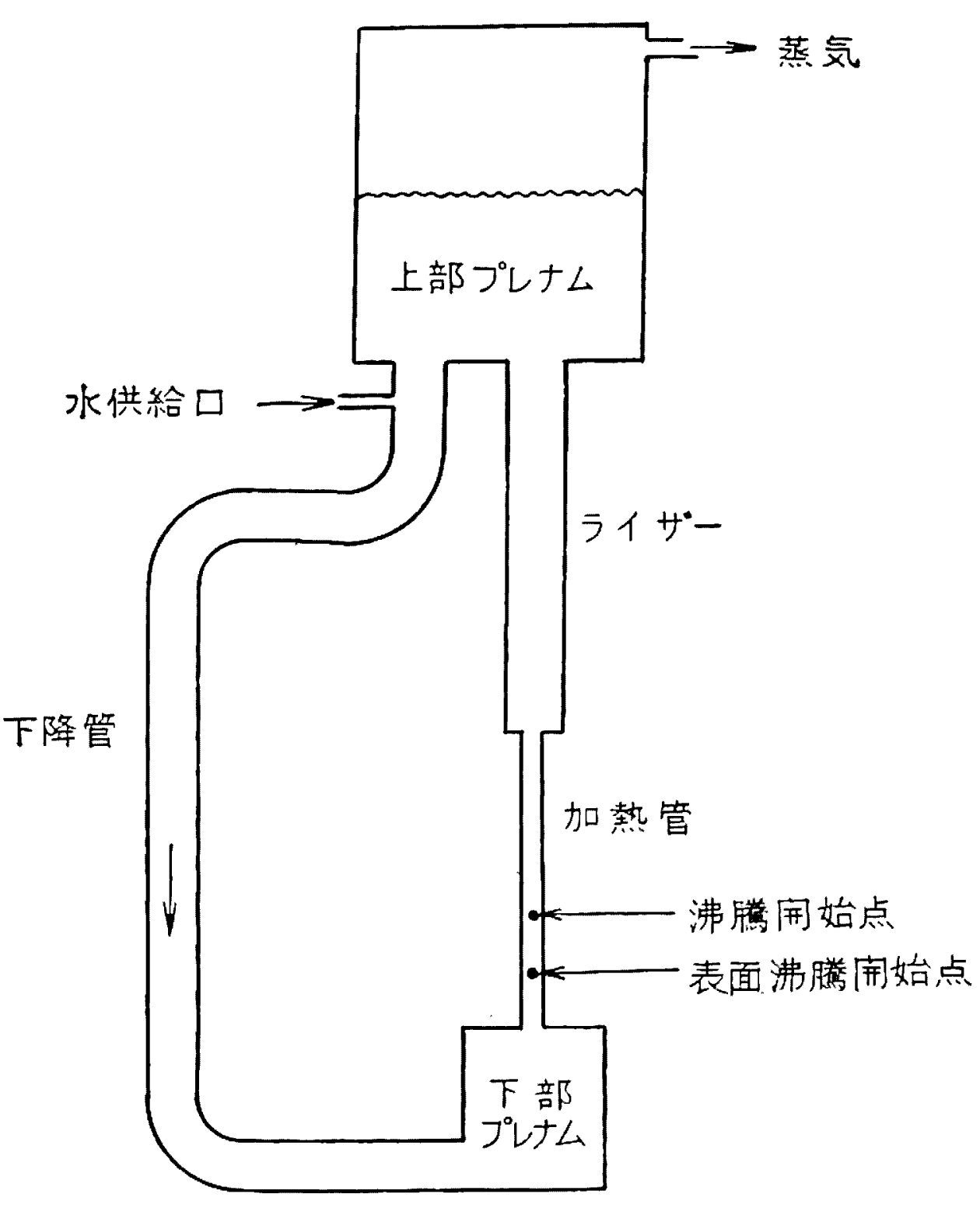

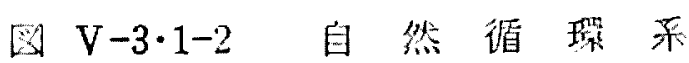

その安定性を検討しなければ不十分である。一般に加熱 量が一定のとき，流量が十分大きければ降下は流量と 共に增すが，流量が小さくなると出口のエンタルピーは 沸滕が起るまで增え，その辺では流量が減ると圧降下が 增える。このため一つの圧降下の值は二つ以上の流量に 対応してこれが不安定の原因になるといわれている8。

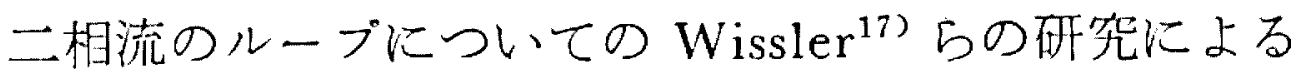
と, $0.872^{\prime \prime}$ 管での実験と解析から入熱が一定で泠却水温 度が一定でも振動が㧍こることがある。

また沸滕水型原子炬に関連して安定性の研究は重要で ある。安定性の計算のためには炉内の㳩特性，特に炉心 内ボイドの動特性が必要であるが，その点に関して多く のモデルが考えられて計算が行なわれているが，ここに は文献名を岗げるに止める20)。

\section{$\mathrm{V}-3 \cdot 1-7$ 結 言}

蒸発装置内の流動の問題としては自然循環または強制 循環の計算が目標で，これには計算法の大網は与壳られ ているが，これに適用する具体的数值になるとまだ十分 とは云光ず，さらに各方面での研究が必恶である。特に 化学装置としての蒸発待では，V-3・1-5に示したよ5に 計算法も複雑でしかも流显分配などの問題や水以外の液 体の問題がでてくるがその方面は未開拓といってよい。 


\section{使 用 記 号}

（化工距擥と同じの，本文中に説明したものはここでは省略した。）

$A$ : 加㷫管断面積, $f_{f}$ : 摩擦係数, $G$ : 質量速度, $h_{f}$ : 館和液エンタルピー, $h_{i}$ : 加篹管入口エンタルピ 一, $h_{f g}$ : 蒸発潜熱, $L_{B}$ : 蒸発の起っている区間長さ, $L_{T}$ : 加筫管全長, $\Delta P_{T P F}$ : 二相流摩擦損失, $\Delta P_{T P}$ : 二相流全王降下, $q^{\prime \prime}$ : 加熱量 B.t.u. $/ \mathrm{hr} \cdot \mathrm{ft}^{2}$ (4 式),

\section{文}

1) Buchberg, H., F. Romer et al.: Heat Transfer and Fluid Mechanics Institute, 1951, p. 177, Stanford University Press

2) Dengler, C. G.: "Heat Transfer and Pressure Drop for Evaporation of Water in a Vertical Tube" PhD Thesis, MIT, 1952

3) Flinn, W. S. \& M. Petrick: "Performance and Potential of Natural Circulation Boiling Reactors" U.S. A. E. C. Report. ANL-5720 (Oct. 1957)

4) Hoopes, J. W. Jr. : A. I. Ch. E. J., 3, 268 (1957)

5) Harvey, B. F. \& A. S. Foust: Chem. Eng. Progress, Symp. Ser., No. 5

6) Isbin, H. S., J. E. Moy \& A. J. DaCruz: A. I. Ch. E. $J ., 3,361$ (1957)

7) Isbin, H. S., R. H. Moen et al.: "Two-Phase Steam. Water Pressure Drops" 4 th Nat1. Nuclear Eng. \& Sci. Conference, Chicago, Ill., 1958, Preprint, No. 147

8) Jens, W. H. \& G. Leppert : J. Am. Soc. Naval Engrs., 67, 437 (1955)

9) Jakob, M., G. Leppert \& J. B. Reynolds: Chem. Eng. Progress, Symp. Ser., No. 18, p. 29 (1956)

10) Lottes, P. A. \& W. S. Flinn: Nucl. Sci. \& Eng., 1, 461 (1956)

11) Lottes, P. A., M. Petrick \& J. F. Marchaterre : "Lecture Notes on Heat Extraction from Boiling Water Power Reactors" U.S. A.E.C. Report, ANL-
$\left(\Delta T_{\text {sub }}\right)_{0}$ : 表面沸勝が始まる点でのサブクーリング， $W_{G}$ : 気相流量 (重量/時間), $W_{L}$ : 漼相流量, $W_{T}$ : 全流量, $x$ : 蒸気乾き扊 $=W_{G} / W_{T}, \bar{\rho}_{D}$ ：下降管内の平

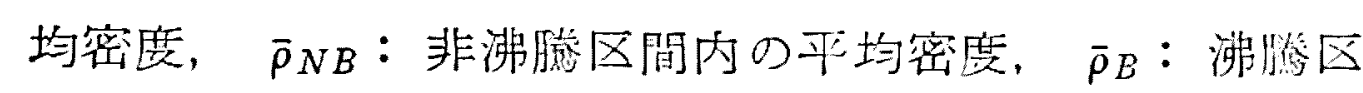
間内の平均密度， $\bar{\rho}_{R}$ : ライザー内の平均密医

献

6063 (Oct. 1959)

12) Lottes, P. A. et al. : Proc. of Second U. N. Intern. Conf. on the Peaceful Uses of Atomic Energy, Vol. 11 (1958)

13) Martinelli, R. C. \& D. B. Nelson: Trans. Am. Soc. Mech. Engrs., 70, 695 (1948)

14) Reynolds, J. B. : "Local Boiling Pressure Drop" U.S. A. E.C. Report, ANL-5178 (1954)

15) Sher, N.C.: "Estimation of Boiling and Non-Boiling Pressure Drop in Rectangular Channels at 2000 psia" U.S. A. E.C. Report, WAPD-TH-300

16) Stein, R. P. et al.: Chem. Eng. Progrcss, Symp. Ser.. No. 11, p. 115 (1954)

17) Wissler, E. H., H. S. Isbin \& N. R. Amundson: A. I. Ch. E. J., 2, 157 (1956)

18) Westmoreland, J. C.: "Prediction of the Pressure Loss and Density Factors for Two.Phase Annular Flow With or Without Heat Generation" U.S. A. E. C. Report, KAPL-1792 (1957)

19）山崎弥三郎：化学工学, 24, 649 (1960)

20) Fleck, J. A. Jr.: J. Nucl. Energy, Pt. A., 11, 114 (1960); Beckjord: "Dynamic Analysis of Natural Circula. tion BWR" U.S. A.E.C. Report, ANL-5799 (1958); Thie, J. A. : "Dynamic Behavior of Boiling Reactor" U.S. A. E.C. Report, ANL-5849 (1959)

\section{$\mathrm{V}-3 \cdot 2$ エントレーメント*}

蒸発缶のエントレーメントが最近特に重要になってき たのは放射性廃液の蒸発処理のためである。製塩工業, 精精工業などの蒸発缶においてもェントレーメントが問 題となるが放射性廃液処理の場合のようには関心がもた れていなかったといえよう。それゆえ，最近の研究報告 は注とんぞ放射性廃液処理の場合に集中されているとい っても過言ではない。放射性廃液処理の場合, 被処理液 中に不揮発性物質の及を含有寸る際汇はその取扱いは通 常の製塩工業、精結工業などの蒸発缶のエントレーメン 卜之全く同樣になる。被処理液中に沃素, ルテニウム， セシウムなどの揮発性物質を含有する際には，液をアル カリ性にして揮発を防止することができる。 蒸発畋のエントレーメントについてはさきに総説で本

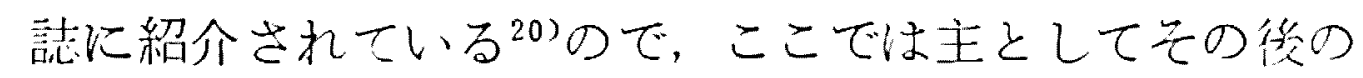
進歩汇ついて繦れてみたい。

エントレーメントの生成機構を単一泡による实䮖から

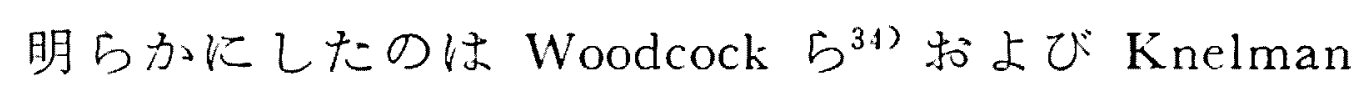

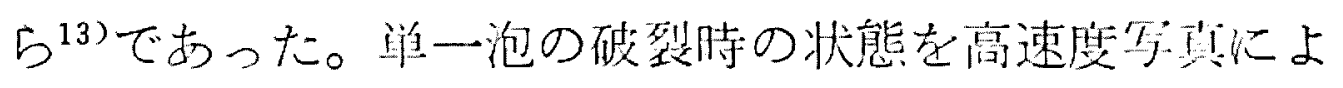
ってとら光, 気池ドームの薄膜破裂によるエントレーメ ントと貲射效果によるェントレーメントがあることを明 らかにした。监一泡の直径と生成液滴粒径との定量的阔 倸は Garner $5^{6)}$, Newitt ${ }^{26)}$, 三石ら ${ }^{19)}$ によって行 な水れている。気泡径が大となると生成する液湖粒径も 大となり， $5 \mathrm{~mm} \phi$ 程度の気泡径沈なると喷射液㵜が生 じなくなる。水の場合については Garner ら拉よび三石 らの結果が比䡆的よく一致している。な拉三石らは液淮

\footnotetext{
* 沼和 36 年 1 月 26 日受理

** 京都大学工学研究所
} 